

e-ISSN: 2146 - 9067

International Journal of Automotive

Engineering and Technologies

journal homepage: http://ijaet.academicpaper.org

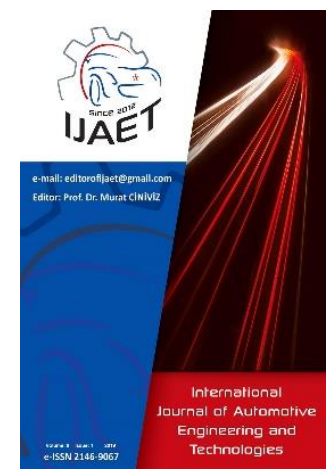

Original Research Article

\title{
Experimental and Numerical Analysis of Laser-ignition of Wet Ethanol with Elevated Water Content
}

\section{Kazi Mostafijur Rahman*1, Nobuyuki Kawahara ${ }^{2}$, and Eiji Tomita ${ }^{2}$}

${ }^{1}$ Department of Mechanical Engineering, Khulna University of Engineering \& Technology, Khulna-9203, Bangladesh.

${ }^{2}$ Heat Power Engineering Laboratory, Okayama University, Tsushima Campus, Okayama 700-8530, Japan.

\begin{abstract}
ARTICLE INFO
* Corresponding author pjk63kj9@s.okayama-u.ac.jp ormostafij@me.kuet.ac.bd

Received: May 17, 2019

Accepted: July 25, 2019

Published by Editorial Board Members of IJAET

(C) This article is distributed by Turk Journal Park System under the CC 4.0 terms and conditions.
\end{abstract}

\begin{abstract}
Higher production cost of anhydrous ethanol associated with distillation and dehydration process could be reduced through the direct use of wet/hydrous ethanol in engine applications. In this study, both experimental investigation and numerical analysis were carried out to quantify the effect of water content on laser ignition characteristics of premixed charge of wet ethanol with different water concentration and over a range of equivalence ratios. Combustion of wet ethanol was initiated through laser-induced breakdown from a Q-switched Nd:YAG laser. A high-speed camera is used to visualize the ignition event and flame propagation. Results demonstrated that, presence of water in ethanol up to $20 \%$ by volume accelerated the initial combustion reactions and led to faster burning. Adverse effects of elevated water concentration in ethanol at and beyond $30 \%(\mathrm{v} / \mathrm{v})$, are more pronounced in fuel lean combustion region compared with fuel rich combustion. Laser-induced breakdown spectroscopic (LIBS) measurements revealed that, plasma temperature slightly increased with added water in ethanol up to $20 \%(\mathrm{v} / \mathrm{v})$ as water in ethanol results in enhanced ionization of the gas mixture during laser breakdown, which leads to more intense absorption of laser energy. Therefore, this study demonstrates the potential of direct use of wet ethanol as an attractive fuel for IC engine.

Keywords: Laser-ignition, Wet Ethanol, Plasma Temperature
\end{abstract}

\section{Introduction}

Ethanol has long been considered as one of the most promising bio-fuels because of its better ignition and emission characteristics, and also for renewable in nature. Use of ethanol as an alternative fuel in transportation sector can contribute to reduce the dependence on fossil fuel and thereby reducing greenhouse gas emissions. In addition, ethanol can act as an octane booster for gasoline [1], it has a higher flame velocity compared to gasoline [2-3] and higher enthalpy of vaporization, allowing engine to run with higher compression ratio, ultimately resulting in higher engine efficiency [4-7]. The results of the engine test showed that using pure ethanol or blends of ethanol-gasoline reduce carbon monoxide $(\mathrm{CO})$ and hydrocarbon (HC) emissions substantially compared with gasoline [8-10].

Production of anhydrous ethanol (less than 1\% water) is energy intensive process and most of 
the energy is required to remove the water content of ethanol through distillation and dehydration process. For the corn-ethanol case, figure 1 [11-13] shows the largest areas of energy utilization in the production of pure ethanol. Prior research has shown that removing the final $20 \%$ of water (and particularly the final $5 \%$ ) from ethanol requires the largest fraction of energy. Therefore, direct use of wet ethanol in engines could improve the associated energy balance.

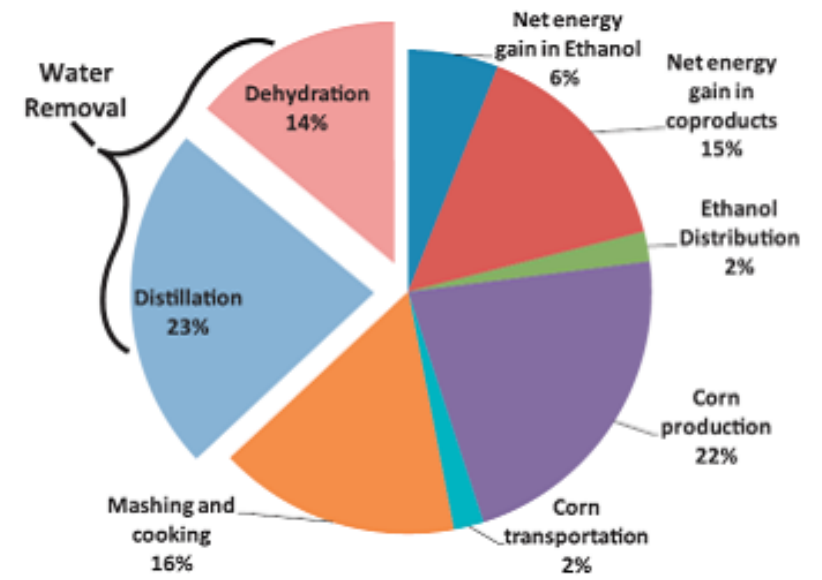

Figure 1. Energy utilization for various stages of corn ethanol production [11-13].

Effect of wet ethanol in different kind of IC engines varying from spray guided direct injection engine to homogeneous charge compression ignition (HCCI) engine was investigated previously [13-15]. Hydrous ethanol with $35 \%$ water content by volume was used in a HCCI engine by Martinez-Frias et al. [13] and reported an increase in brake thermal efficiency up to $38.7 \%$, and $1.6 \mathrm{ppm}$ of NOx. Later they demonstrated stable HCCI engine operation while running the engine with ethanol containing up to $40 \%$ water content by volume [15]. Olberding et al. [16] investigated the engine performance of a transit van operating on either gasoline or ethanol-water fuel mixtures (70\% ethanol with $30 \%$ water). They reported that by using wet ethanol, engine thermal efficiency can be increased significantly with substantial reduction in NOX and CO emissions compared to gasoline fuel.

Several high energy ignition methods have been proposed due to the limitations associated with convention electrical spark ignition system [17]. Laser ignition is continuing to gain attention all over the world because it offers some significant advantages over conventional spark ignition such as: (a) absence of electrodes which can disturb the cylinder geometry and hence there is no quenching effect on the developing flame kernel, (b) variable ignition positions within a cylinder/combustion chamber enabling ignition at location of ideal air-fuel ratio through which minimum ignition energy threshold can be reduced, (c) possibility of multiple ignition positions in time and space thus yielding shorter combustion times, shorter ignition delay times and higher peak pressures, (d) can ignite leaner or high pressure mixtures. As a consequence the flame temperature is lowered, NOx emissions improved whereas engine efficiency can be increased simultaneously; others remarkable advantages are precise ignition timing, more stable combustion [18-25].

Laser-induced breakdown spectroscopy (LIBS) is proved to be a promising diagnostic technique which allows both qualitative or quantitative analysis of complex phenomenon such as study of plasma, ignition characteristics or combustion flame etc. LIBS technique find its applications in many fields, such as environmental monitoring, production control of steel, material sorting, toxic substance detection, and removal of coatings [26]. LIBS of gases are possible using high power laser pulses. When a short-pulse laser is focused into air or other gases, the laser beam creates localized plasma. The collection and spectral analysis of the plasma emissions allows the qualitative identification of atomic species [27]. Ferioli et al. discussed the applicability of LIBS for measurements in a combustion system [28]. Phuoc et al. have studied the simultaneous laser ignition and equivalence ratio measurement using laser-induced gas breakdown in methaneair and hydrogen/air mixtures using $\mathrm{H} \alpha(656$ $\mathrm{nm}$ ) and the O triplet near $777 \mathrm{~nm}$ [29]. Ikeda and Kawahara et al. also tried to measure the equivalence ratio using LIBS and discussed the accuracy of spatially, temporally, and spectrally resolved measurements of laser induced plasma in air [30, 26].

In this study, laser ignition of hydrous/wet ethanol was investigated emphasizing primarily on the effect of water content on laser ignition characteristics. Laser-induced breakdown was generated by focusing a $532 \mathrm{~nm}$ nanosecond pulse from a Q-switched Nd:YAG laser. Experiments on laser ignition characteristics of premixed charge of wet ethanol with different 
water concentration by volume $(0 \%-40 \%)$ and over a range of equivalence ratios $(0.7-1.2)$ were carried out. Time-series images of flame propagation were obtained through a high-speed camera. Based on mass fraction burned and post analysis of raw flame images, laser ignition delay was determined. To further quantify the effect of water concentration in ethanol, spectroscopic analysis of plasma emission was conducted and plasma temperature was estimated through laser-induced breakdown spectroscopy (LIBS). Numerical investigation on the flame characteristics was performed through the use of commercial software CHEMKIN-PRO.

\section{Experimental Setup and Methods}

Figure 2 shows the schematic of the experimental setup. Fuel is injected into the constant volume chamber (CVV) through a DISI 6-hole injector at injection pressure of $P_{i n j}$ $=5 \mathrm{MPa}$. To attain premixed charge of fuel-air through evaporation and subsequent mixing of hydrous/wet ethanol with the ambient air inside the chamber and to maintain the preheat temperature (unburnt mixture temperature) at $T_{a}$ $=430 \mathrm{~K}$; an electric heater with magnetic stirrer is used. The CVV has four quartz windows to provide optical access for visualization of flame propagation and for spectroscopic measurements (see Figure 3). Combustion of ethanol was initiated through laser-induced breakdown generated by focusing a nanosecond (pulse duration $=8 \mathrm{~ns}$ ) second harmonic (wavelength $=532 \mathrm{~nm}$, beam diameter $=8 \mathrm{~mm}$ ) pulse of Q-switched Nd:YAG laser (Spectra Physics, Lab series-150) through the optical window of the chamber. Laser beam was focused using a plano-convex lens with focal length of $100 \mathrm{~mm}$. Incident beam energy was adjusted by a half-wave plate and a polarizing beam splitter, and maintained at Ein $=30 \mathrm{~mJ}$. For spectroscopic analysis (LIBS analysis), emission from the laser-induced plasma was led to the spectrometer (Andor SR-163 and MK300) coupled with ICCD detector (iStar DH720 and iStar DH320T) through an optical fiber. Wavelength calibration was performed using a 'mercury-argon lamp'. For plasma temperature measurement, calibration was performed taking into account the quantum efficiency as a function of wavelength. Here, the spectral coverage was in the range of $250 \mathrm{~nm}-850 \mathrm{~nm}$ with resolution about 1 ns. Effective pixel size of $26 \mu \mathrm{m}$ and grating of 150 line $/ \mathrm{mm}$ were used for spectroscopic measurements.

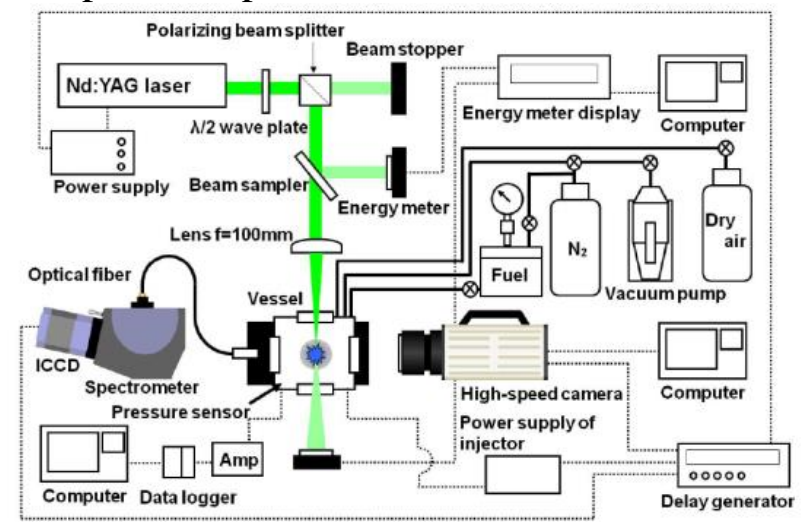

Figure 2: Schematic diagram of Experimental Setup
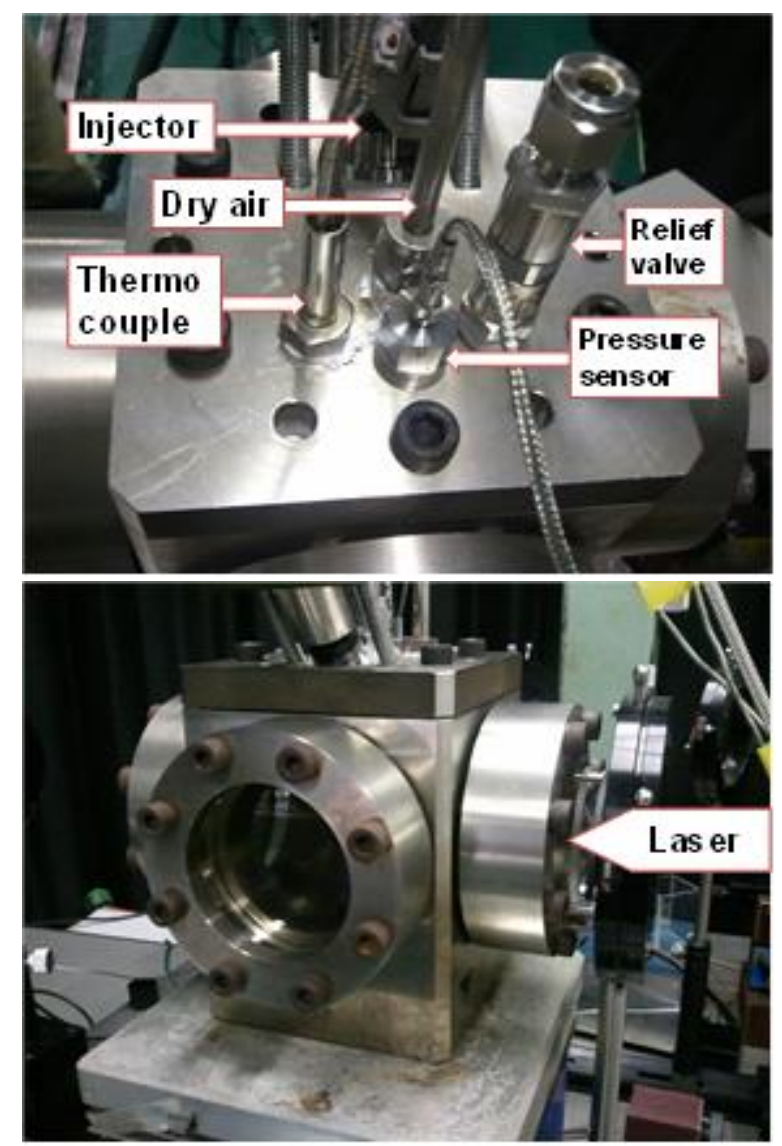

Figure 3: Photograph of constant volume chamber

A high-speed camera (nac Image Technology Inc., MEMRECAM GX-8) was operated at the speed of 10,000 frames per second with a resolution of $576 \times 576$ pixels to visualize plasma generation and subsequent flame propagation. In-chamber pressure history for combustion of ethanol was recorded by using a piezo-electric pressure transducer (Kistler 6052C) with charge amplifier (Kistler 5011B). For synchronization and precise control of the operation timing, experimental devices were 
connected to a delay generator (Stanford Research System Inc., DG645).

To prepare the fuel mixture, water was added and mixed with dehydrated ethanol at different ratios (10-40 \%) by volume basis and stored in a fuel accumulator. After the injection of hydrous ethanol, the charge was stirred for 40 minutes in order to make premixed charge of ethanol-water-air. Details on selecting appropriate stirring duration could be found in the previous report [31].

\section{Results and Discussion}

\subsection{Laser ignition delay characteristics of wet ethanol}

To quantify the effect of water content on laser ignition characteristics of wet ethanol, initially, the time required for $0.1 \%$ MFB (mass fraction burned) is defined arbitrarily as laser ignition delay. However, to avoid inaccuracy in calculating MFB due to the noise present in raw pressure data, equivalent flame area corresponding to $0.1 \%$ MFB was considered for the comparison. Flame images were processed and analysed by using MATLAB to estimate equivalent flame area. At first, raw flame images were converted to grayscale images, and then binary images were obtained by thresholding the grayscale images of the flame. Figure 4 illustrates the intermediate steps in determining the flame contour from raw flame images. The flame kernel was found to be toroidal, with a front lobe propagating back toward the incoming laser, which is consistent with several previous reports [32-34]. The laser ignition delays as a function of water content over the equivalence ratios ranging, from $\phi=$ 0.7 to $\phi=1.2$ and the initial temperature of $\boldsymbol{T}_{\boldsymbol{a}}=$ $430 \mathrm{~K}$, are plotted in Figure 5. It can be observed from the figure that laser ignition delay becomes shorter with the addition of small amount of water up to $20 \%(\mathrm{v} / \mathrm{v})$ in ethanol. The delay was found to be shortest for ethanol mixed with $10 \%$ water (v/v). In our previous study [31], it was hypothesized that, the generation of radicals such as $\mathrm{OH}^{*}$ could be enhanced during the laserinduced breakdown due to the presence of water in ethanol which accelerated the initial combustion reactions and lead to faster combustion rates. This enhancement in radical generation is also reported in a recent study by Feng et al. [35]. Figure 5 clearly demonstrates that the adverse effects of elevated water concentration in ethanol. It is more pronounced in lean combustion region compared with fuel rich combustion. For example, in case of $\phi=$ 0.7 , laser ignition delay for water concentration of $30 \%-40 \%$ become almost double than that for water concentration of $0 \%-20 \%$. For volume fraction of water beyond $20 \%$; physical and chemical influences of the water in the mixture of ethanol-water, such as, dilution effect and reduction in burning velocity appear to offset the improved radical concentration and mixture reactivity.

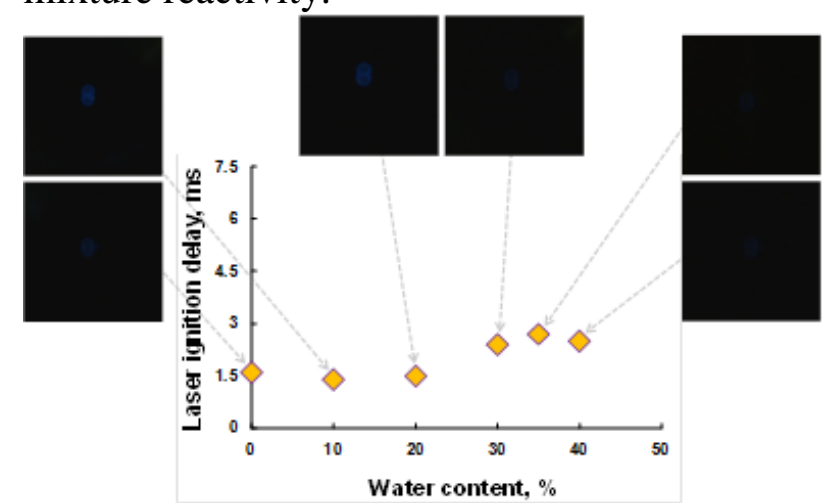

(a) Raw flame images; $\phi=1.0$, Water $(\mathrm{v} / \mathrm{v})=0 \sim 40 \%, \mathrm{~T}_{\mathrm{a}}$ $=430 \mathrm{~K}$

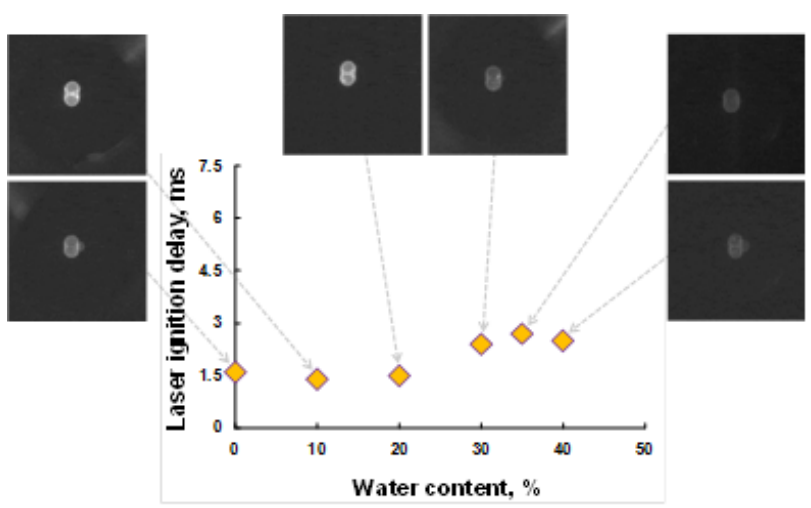

(b) Grey-scale flame images; $\phi=1.0$, Water $(\mathrm{v} / \mathrm{v})=0 \sim$ $40 \%, \mathrm{~T}_{\mathrm{a}}=430 \mathrm{~K}$

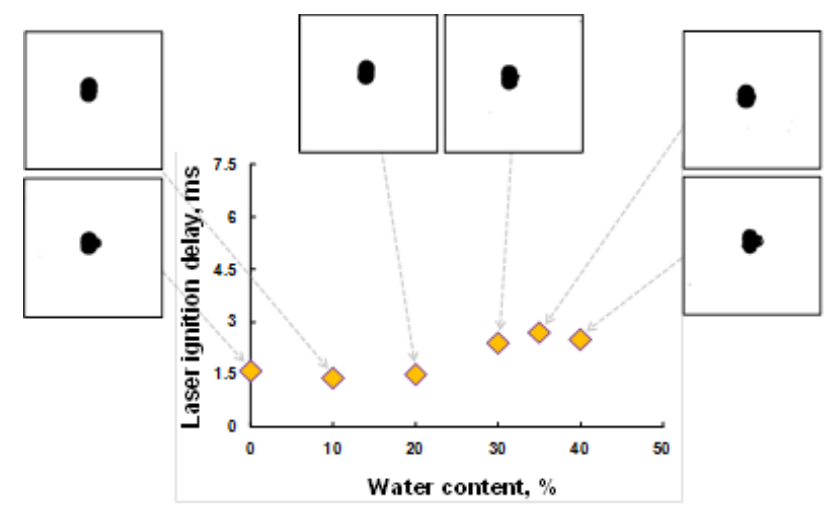

(c) Flame contour; $\phi=1.0$, Water $(\mathrm{v} / \mathrm{v})=0 \sim 40 \%, \mathrm{~T}_{\mathrm{a}}=$ $430 \mathrm{~K}$

Figure 4: Flame contour detection to define the laser ignition delay of wet ethanol 


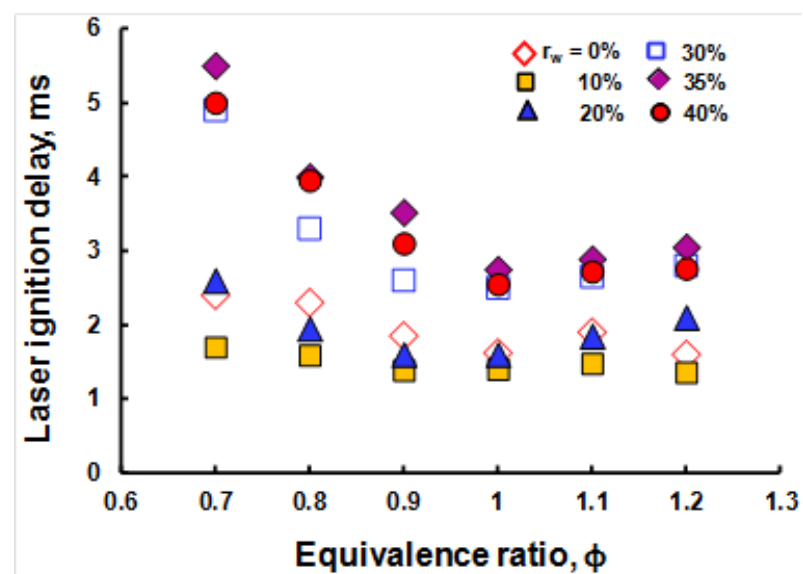

Figure 5: Effect of water content (in the range 0-40\%), on laser ignition delay of wet ethanol

\subsection{Laser-induced breakdown spectroscopy (LIBS) of wet ethanol}

Laser-induced breakdown spectroscopy (LIBS) was employed in this study to detect the atomic emission from laser-induced plasma and afterward the plasma temperature was estimated by using the Boltzmann equation [36-38] with the assumption that laser-induced plasma was in local thermodynamic equilibrium. In Boltzmann equation the emission intensities (integrated over the spectral profiles) from two transitions $\left(I_{1}\right.$ and $\left.I_{2}\right)$ are related to the transition probabilities $\left(\mathrm{A}_{1}\right.$ and $\left.\mathrm{A}_{2}\right)$, the transition wavelengths $\left(\lambda_{1}\right.$ and $\left.\lambda_{2}\right)$, the statistical weights of the upper level of the transition $\left(\mathrm{g}_{1}\right.$ and $\left.\mathrm{g}_{2}\right)$, the energies of the upper states $\left(\mathrm{E}_{1}\right.$ and $\left.\mathrm{E}_{2}\right)$, the temperature $(\mathrm{T})$, and the Boltzmann's constant (k) according to:

$\frac{I_{1}}{I_{2}}=\frac{g_{1} A_{1} \lambda_{1}}{g_{2} A_{2} \lambda_{2}} \exp \left\{-\frac{E_{1}-E_{2}}{k T}\right\}$

With the natural logarithms of Equation (1) a linear equation between the differences in the weighted intensities and the upper-state energies E is obtained:

$\ln \left(\frac{I_{1} \lambda_{1}}{g_{1} A_{1}}\right)-\ln \left(\frac{I_{2} \lambda_{2}}{g_{2} A_{2}}\right)=-\frac{E_{1}-E_{2}}{k T}(2)$

Due to the linear relationship plotting $\ln (\mathrm{I} \lambda / \mathrm{Ag})$ as a function of the upper state energy E permit to obtain a slope equal to $(-1 / k T)$. Plasma temperature can be estimated using different emission line of same gas species, as follows:

$$
T=\frac{E \prime_{k}-E_{k}}{k \ln \left(\frac{\varepsilon_{k i}}{\varepsilon^{\prime}{ }_{k i}} \frac{\lambda_{k i}{ }^{\prime}{ }_{k i} g^{\prime} k i}{\lambda^{\prime}{ }_{k i} A_{k i} g_{k i}}\right)}
$$

In these experiments, plasma emission lines of $\mathrm{H}_{\alpha}(656 \mathrm{~nm})$ and $\mathrm{H}_{\beta}(486 \mathrm{~nm})$ were considered to estimate plasma temperature. Emission spectra for laser induced plasma in ethanol were obtained using spectrometer with ICCD detector. Plasma emissions lines of C at $247 \mathrm{~nm}$, $\mathrm{H}_{\alpha}$ at $656 \mathrm{~nm}, \mathrm{H}_{\beta}$ at $486 \mathrm{~nm}, \mathrm{~N}(\mathrm{I})$ at $501 \mathrm{~nm}$ and $\mathrm{O}(\mathrm{I})$ at $777 \mathrm{~nm}$ were clearly recorded as shown in Figure 6. The intensity of $\mathrm{H}_{\alpha}$ line was due to the electronically excited hydrogen dissociated from the fuel and water molecules, while the emissions of $\mathrm{N}(\mathrm{I})$ and $\mathrm{O}(\mathrm{I})$ lines were obtained from electronically excited nitrogen and oxygen, respectively, dissociated from air [29]. Figure 7 shows the effect of water concentration on background-corrected atomic emission intensity ratio of $\mathrm{H}_{\alpha}$ and $\mathrm{N}(\mathrm{I})$ during laserinduced breakdown in wet ethanol. In spectroscopic measurements and analyses, when the intensities of some elements become the subject of interest, it is necessary to subtract the background from the raw spectrum data. Here, background was subtracted from the raw spectra following the method suggested by Proctor and Sherwood [39] in order to obtain the background corrected intensities for $\mathrm{H}_{\alpha}, \mathrm{N}(\mathrm{I})$ and $\mathrm{H}_{\beta}$ emission lines. Details of the calibration and background subtraction methods can be found in Ref. [40]. From Figure 7, it is evident that the intensity ratio of $\mathrm{H}_{\alpha}$ to $\mathrm{N}(\mathrm{I})$ increases gradually with the addition of water in ethanol. For elevated water content, presence of total hydrogen molecule in the mixture became higher which subsequently increased the emission intensity of $\mathrm{H}_{\alpha}$ through laser induced breakdown, thereby increasing intensity ratio of $\mathrm{H}_{\alpha}$ to $\mathrm{N}(\mathrm{I})$.

In order to further look at the effect of water content in ethanol, plasma temperatures were estimated by, considering atomic emission of $\mathrm{H}_{\alpha}$ and $\mathrm{H}_{\beta}$ lines from LIBS spectra, using Boltzmann equation where spectroscopic constants for $\mathrm{H}_{\alpha}$ and $\mathrm{H}_{\beta}$ lines were obtained from NIST database [41]. From figure 8 , it is found that, plasma temperatures slightly increased with addition of water in ethanol up to $20 \%(\mathrm{v} / \mathrm{v})$, whereas for water concentration of $30 \%$ and $40 \%(\mathrm{v} / \mathrm{v})$, reduction in plasma temperature could be observed. This might be due to the fact that the ionization of the gas mixture during laser breakdown could be enhanced by the presence of water in ethanol, which results in more intense absorption of laser energy. However, reduction in plasma 
temperatures, might be attributed to the quenching effect of diluted mixture and chemical influence of elevated water concentration in ethanol.

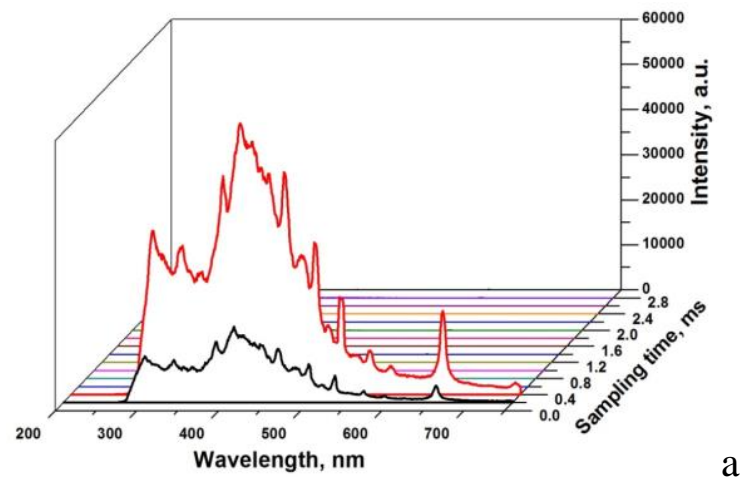

a

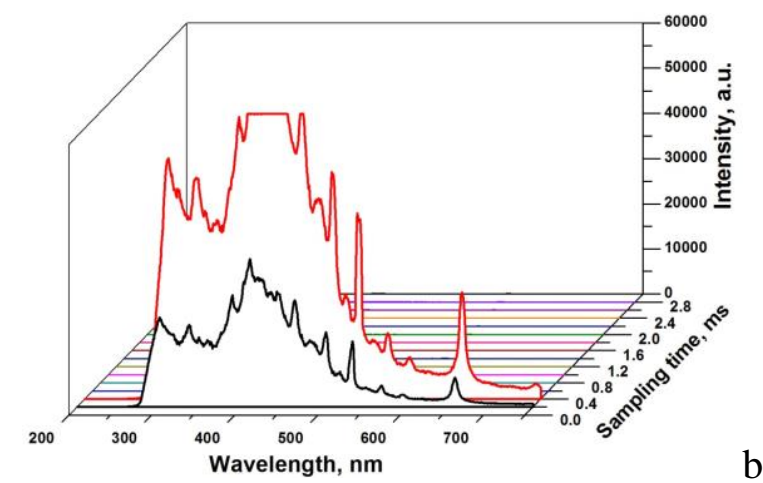

$\mathrm{b}$

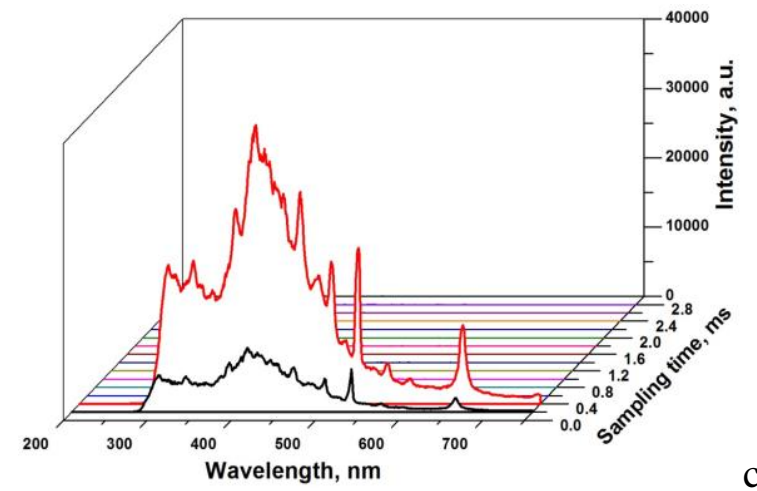

Figure 6: LIBS spectra for laser-induced breakdown in wet ethanol, $\phi=1.0$, and $\boldsymbol{T}_{\boldsymbol{a}}=430 \mathrm{~K}$; (a) for anhydrous ethanol (i.e. $0 \%$ water by volume), (b) with $20 \%$ water by volume, (c) with $40 \%$ water by volume

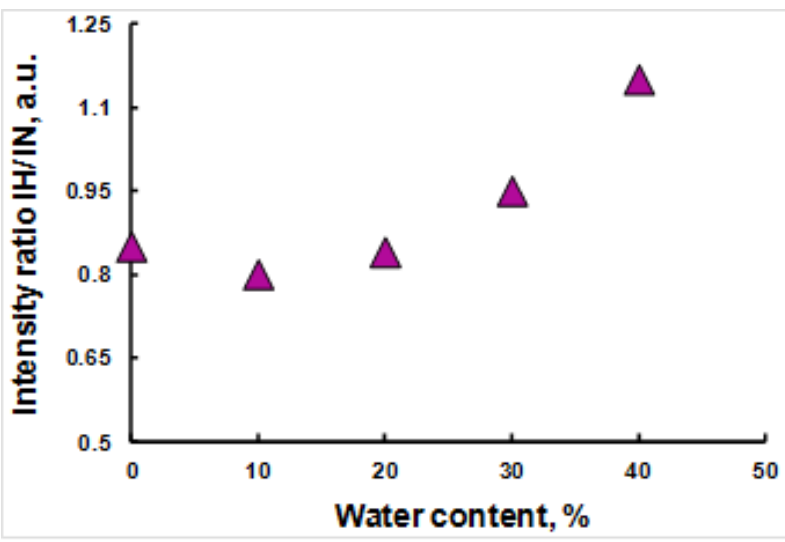

Figure 7: Effect of water content on intensity ratio of $\mathrm{H}_{\alpha} / \mathrm{N}$ for wet ethanol with water content (v/v) $=0 \sim 40 \%$, $\phi=1.0$, and $\boldsymbol{T}_{\boldsymbol{a}}=430 \mathrm{~K}$

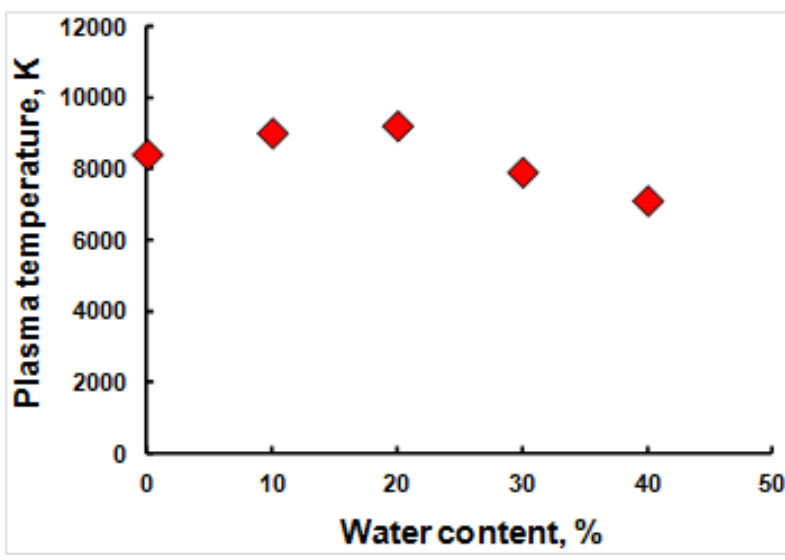

Figure 8: Effect of water content on plasma temperature for breakdown in wet ethanol with water content $(\mathrm{v} / \mathrm{v})=$ $0 \sim 40 \%, \phi=1.0$, and $\boldsymbol{T}_{\boldsymbol{a}}=430 \mathrm{~K}$

\subsection{Numerical analysis on the effect of water content on flame characteristics}

Previously we hypothesized that laminar burning velocity decreased due to the dilution effect of water in the mixture of ethanol-water. So, it becomes quite necessary to investigate effect of water on the flame characteristics of wet ethanol and as a consequence we employed the commercial software package CHEMKINPRO [42] for numerical investigation. For CHEMKIN analysis, here we have selected the most well-known oxidation mechanism for ethanol combustion presented by Marinov et al. [43]. In Marinov's mechanism there are 57 chemical species and 383 reversible reactions. This model has been validated against a number of experiments and is widely accepted.

The Premixed Flame-speed Calculator in CHEMKIN-PRO simulates a freely propagating one-dimensional planar flame, in which the point of reference is a fixed position on the flame. The Premixed Flame Models solve the set of governing differential equations that describe the flame dynamics using implicit finite difference methods, as well as, a combination of time-dependent and steady-state methods.

\subsubsection{Adiabatic flame temperature}

The adiabatic flame temperature is a measure of the maximum temperature that could be reached by combusting a particular gas mixture under a specific set of conditions. Both burning velocity and combustion efficiency are significantly affected by adiabatic flame temperature.

Figure 9 shows the effect of water addition (up to $40 \%$ by volume) on reduction in adiabatic 
flame temperature over a range of equivalence ratios and initial charge temperatures. The plot demonstrates that reduction in flame temperature due to water addition becomes higher as equivalence ratio increases and initial charge temperature decreases. Moreover, it is also evident that above $\phi=1.0$, flame temperature reduction becomes more stepper than that for equivalence ratio $(\phi)$ below 1.0. Thus, chemical influence of water in ethanol was more pronounced in fuel rich combustion with lower initial temperature compared to lean combustion with higher initial charge temperature.

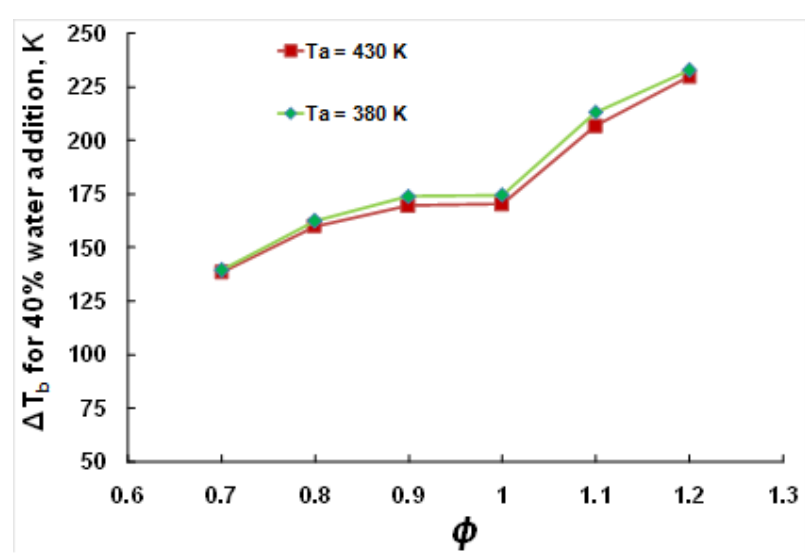

Figure 9: Effect of water addition (up to 40\%) on reduction in adiabatic flame temperature as a function

E.R $(\phi)$ and at different initial mixture temperature

\subsubsection{Planar flame structure}

Figure 10 shows the predicted planar flame structures and concentrations of the major species in premixed ethanol flame with different water contents. It is evident in these figures, as the reactions proceed, the reactants $\mathrm{C}_{2} \mathrm{H}_{5} \mathrm{OH}$ and $\mathrm{O}_{2}$ decrease rapidly, whereas the products of combustion $\mathrm{H}_{2} \mathrm{O}$ and $\mathrm{CO}_{2}$ increase further downstream of the flame as would be expected. With the addition of water in ethanol as diluent, mole fractions of $\mathrm{C}_{2} \mathrm{H}_{5} \mathrm{OH}$ and $\mathrm{O}_{2}$ as reactants decrease gradually. Due to the dilution and chemical influences of elevated water content, final mole fraction of $\mathrm{CO}$ decreases with higher water content, while this increases for $\mathrm{H}_{2} \mathrm{O}$. Rapid oxidation of $\mathrm{CO}$ into $\mathrm{CO}_{2}$ occurs due to the higher concentration of $\mathrm{OH}$ in the reaction zone within the flame, leading to the decrease of $\mathrm{CO}$ concentration after a certain level.

\section{Conclusions}

Experimental and numerical investigations on laser ignition of hydrous/wet ethanol have been performed with water content varying from 0 $40 \%$ by volume and over a range of equivalence ratios (0.7 to 1.2$)$.

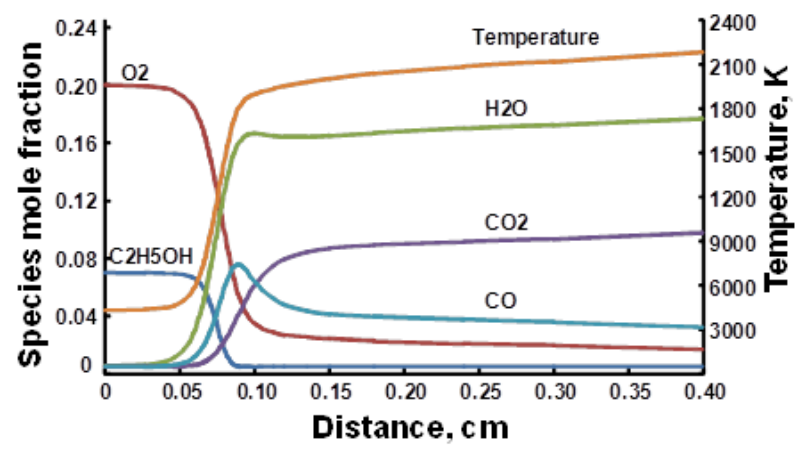

a Water content $=0 \%$

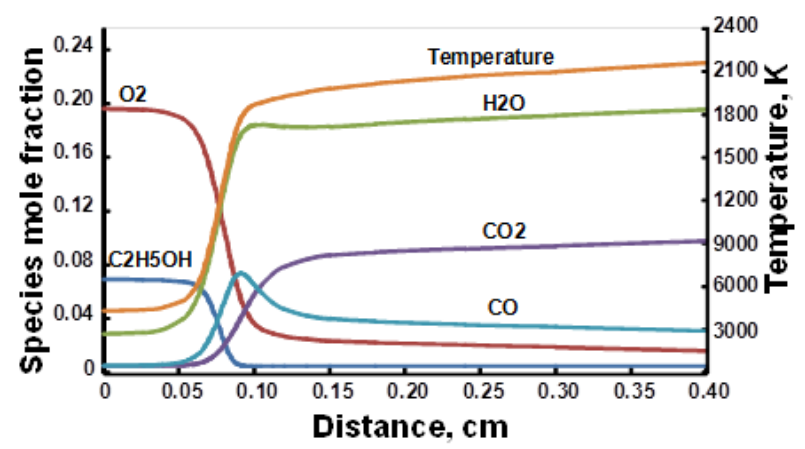

b Water content $=10 \%$

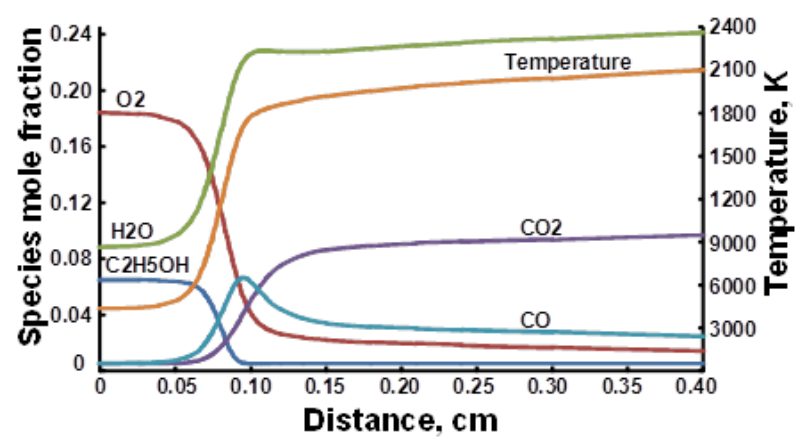

c Water content $=30 \%$

Figure 10: Flame structure for stoichiometric premixed combustion of ethanol with different water content and at initial temperature of $430 \mathrm{~K}$

In order to quantify the effect of water content on laser ignition characteristics of ethanol, high speed visualization of combustion flame was carried out. Laser ignition delay was defined arbitrarily and estimated from both the mass fraction burned and equivalent flame area. Laser-induced breakdown spectroscopic (LIBS) analysis were carried to evaluate the influence of water in ethanol on atomic emission intensities and plasma temperature. The flame characteristics like adiabatic flame temperature and planar flame structure were investigated through the use of commercial software package CHEMKIN-PRO. The major conclusions drawn from this study are as follows: 
1. Presence of water in ethanol up to $20 \%$ $(\mathrm{v} / \mathrm{v})$ accelerated the initial combustion reactions and lead to faster burning rates. For elevated water concentration i.e. $30 \%-40 \%$ (v/v) in ethanol, deterioration in combustion characteristics becomes evident.

2. Ionization of the gas mixture during laser breakdown enhanced due to addition of water in ethanol up to $20 \%(\mathrm{v} / \mathrm{v})$, which leads to more intense absorption of laser energy, resulting in higher plasma temperature. For water concentration of $30 \%$ and more, reduction in plasma temperature could be observed due to the quenching effect of diluted mixture and chemical influence of elevated water concentration in ethanol.

3. Dilution effect and chemical influence of water in ethanol was more pronounced in fuel rich combustion with lower initial temperature compared to lean combustion with higher initial charge temperature.

4. Distillation and dehydration of wet ethanol, especially removing the final $20 \%$ of water from ethanol requires the largest fraction of energy, but this study demonstrates the potential of direct use of wet ethanol as an attractive fuel for IC engine.

\section{Conflicts of Interest}

The authors declare that there are no conflicts of interest regarding the publication of this paper.

\section{Acknowledgments}

This study was supported by JSPS KAKENHI Grant Numbers 22246025 and 25249015.

\section{References}

1. Silva RD, Cataluña R, Menezes EW, Samios D, Piatnicki CMS. Effect of additives on the antiknock properties and Reid vapor pressure of gasoline. Fuel 2005;84:951-59.

2. Hara T, Tanoue K. Laminar flame speed of ethanol, n-heptane, iso-octane air mixtures. SAE paper 2006-05-0409; 2006.

3. Beeckmann J, Röhl O, Peters N. Numerical and experimental investigation of laminar burning velocities of iso-octane, ethanol and n-butanol. SAE paper 2009-01-2784; 2009.

4. Nakata K, Utsumi S, Ota A, Kawatake K, Kawai Y, Tsunooka T. The effect of ethanol fuel on a spark ignition engine. SAE paper 2006-01-3080; 2006.

5. Wyszynski LP, Stone R, Kalghatgi GT. The volumetric efficiency of direct and port injection gasoline engines with different fuels. SAE paper 2002-01-0839; 2002.

6. Wallner T, Miers SA. Combustion behavior of gasoline and gasoline/ethanol blends in a modern direct-injection 4-cylinder engine. SAE paper 200801-0077; 2008.

7. Niven RK. Ethanol in gasoline: environmental impacts and sustainability review article. Renew Sustain Energy Rev 2005;9:535-55.

8. Costa RC, Sodre JR. Hydrous ethanol vs. gasoline-ethanol blend: engine performance and emissions. Fuel 2009;89:287-93.

9. Agarwal AK. Biofuels (alcohols and biodiesel) applications as fuels for internal combustion engines. Prog Energy Combust Sci 2006;33:233-71.

10. R Chen RH, Chiang LB, Wu MH, Lin TH. Gasoline displacement and NOx reduction in an SI engine by aqueous alcohol injection. Fuel 2009;89:604-10.

11. Shapouri H, Duffield JA, Graboski MS. Estimating the net energy balance of corn-ethanol. USDA Economic Research Service Report No. AER-721, Washington, DC; 1995.

12. Shapouri H, Duffield JA, Wang M. The energy balance of corn ethanol revisited. ASAE Trans 2003;46(4):959-68.

13. Martinez-Frias J, Aceves SM, Flowers DL. Improving ethanol life cycle energy efficiency by direct utilization of wet ethanol in HCCI engines. J Energy Reso Techn (Trans ASME) 2007;129(2):332-7

14. Brewster S, Railton D, Maisey M, Frew R. The effect of E100 water content on high load performance of a spray guide direct injection boosted engine. SAE paper 2007-01-2648; 2007.

15. Mack JH, Aceves SM, Dibble RW. Demonstrating direct use of wet ethanol in a homogeneous charge compression ignition (HCCI) engine. Energy 2009;34:782-7.

16. Olberding J, Beyerlein DCS, Steciak J, Cherry M. Dynamometer testing of anethanol-water fueled transit van. SAE paper 2005-01-3706; 2005. 17. Dale JD, Checkela MD, Smy PR. Application of High Energy Ignition Systems to Engines. Prog Energy Combust Sci 1997;23:37998.

18. Phuoc TX. Laser-induced spark ignition: fundamentals and applications. Opt Lasers Eng 2006;44:351-97.

19. Dale JD, Smy PR and Clements RM. Laser ignited internal combustion engine: An experimental study. SAE 780329; 1978.

20. Tauer J, Kofler H, and Wintner E. Laserinitiated ignition. Laser Photon Rev 2010; 4:99-122. 21. TX Phuoc. Single-point versus multi-point laser ignition: experimental measurements of 
combustion times and pressures. Combust Flame 2000;122:508-10.

22. Morsy MH and Chung SH. Laser induced multi-point ignition with a single-shot laser using two conical cavities for hydrogen/air mixture. Exp Therm Fluid Sci 2003;27:491-7.

23. Dodd R, Mullett JD, Carroll S, Dearden G, Shenton AT, Watkins KG, Triantos G, Keen S. Laser ignition of an IC test engine using an Nd: YAG laser and the effect of key laser parameters on engine combustion performance. Lasers Engineering 2007;17:213-31.

24. Nobuyuki Kawahara, Kazuya Tsuboi, Eiji Tomita. Laser-induced plasma generation and evolution in a transient spray. Optics Express, 22-S1, (2014) A44-A52.

25. Srivastava DK, Agarwal AK. Comparative experimental evaluation of performance, combustion and emissions of laser ignition with conventional spark plug in a compressed natural gas fuelled single cylinder engine. Fuel 2014;123:11322

26. Kawahara N, Beduneau JL, Nakayama T, Tomita E, Ikeda Y. Spatially, temporally and spectrally resolved measurement of laser induced plasma in air. Appl Phys B Laser Opt 2007;86(4):605e14.

27. N. Kawahara, E. Tomita, S. Takemoto, Y. Ikeda. Fuel concentration measurement of premixed mixture using spark-induced breakdown spectroscopy. Spectro Acta Part B 2009;64(10):1085-1092

28. F. Ferioli, S.G. Buckley, Measurements of hydrocarbon using laser-induced breakdown spectroscopy, Combust. Flame 144 (2006) 435-447. 29. T.X. Phuoc, Laser-induced spark for simultaneous ignition and fuel-to-air ratio measurements, Opt. Lasers Eng. 44 (2006) 520-534. 30. Y. Ikeda, A. Nishiyama, N. Kawahara, T. Nakayama, E. Tomita, Local Equivalence Ratio Measurement of CH4/air and C3H8/air Laminar Flames With and Without Flame Front by LIBS. Sect. 5, LIBS2006, 2006.

31. Rahman K.M., Kawahara N., Tsuboi K. and Tomita E. Combustion characteristics of wet ethanol ignited using a focused Q-switched Nd:YAG nanosecond laser. Fuel 165 (2016) 331-340.

32. El-Rabii H, Rolon JC. Experimental study of laser ignition of a methane/air mixture by planar laser-induced fluorescence of $\mathrm{OH}$. Proceeding of PSFVIP-4, F4022, Chamonix-France 3-5 June, 2003.

33. Spiglanin TA, Mclloroy A, Fournier EW, Cohen RB, Syage JA. Time-resolved imaging of flame kernels:laser spark ignition of $\mathrm{H} 2 / \mathrm{O} 2 / \mathrm{Ar}$ mixtures. Combust Flame 1995;102:310-28.

34. Morsy $\mathrm{MH}$ and Chung SH. Numerical simulation of front lob formation in laser- induced spark ignition of $\mathrm{CH} 4 /$ air mixtures. Proc Combust Inst 2002;29:1613-9.

35. M Feng, XZ Jiang, W Zeng, KH Luo, $\mathrm{P}$ Hellier. Ethanol oxidation with high water content: A reactive molecular dynamics simulation study. Fuel 2019; 235: 515-521

36. L. J. Radziemski, T. R. Loree, D. A. Cremers and N. M. Hoffman. Time-resolved laserinduced breakdown spectrometry of aerosols. Anal. Chem., 55 (1983), 1246-1252.

37. S. Yalçin, D.R. Crosley, G.P. Smith, G.W. Faris. Infuence of ambient conditions on the laser air spark. Appl. Phys. B 68 (1999) 121-130.

38. Leon J. Radziemski, David A. Cremers, Handbook of Laser Induced Breakdown Spectroscopy, John Wiley \& Sons, 2006.

39. A. Proctor, P. M. A. Sherwood. Data analysis techniques in $\mathrm{X}$-ray photoelectron spectroscopy. Anal. Chem., 54 (1) (1982) 13-19.

40. Rahman K.M., Kawahara N., Matsunaga D., Tsuboi K., Tomita E., Takagi Y. and Mihara Y., "Local fuel concentration measurement through spark-induced breakdown spectroscopy in a directinjection hydrogen spark-ignition engine", Int $\mathrm{J}$ Hydrogen Energy 41 (2016) 14283-14292.

41. NIST electronic database, at http://physics.nist.gov/PhysRefData/ASD/lines_for $\underline{\text { m.html }}$

42. http://www.reactiondesign.com/products/ch emkin/chemkinpro/.

43. Marinov NM. A detailed chemical kinetic model for high temperature ethanol oxidation. I J Chem Kinetics 1999;31:183-220. 